\title{
Dose Pattern Evolution and Therapeutic Benefit in Patients on Solifenacin or Fesoterodine Treatment in Daily Clinical Practice
}

\author{
José M. García-Mediero1, Francisco Sánchez-Ballester ${ }^{2}$, Daniel Arumi³, Isabel Lizarraga ${ }^{*}$ \\ ${ }^{1}$ Department of Urology, Hospital MD Anderson, Madrid, Spain \\ ${ }^{2}$ Department of Urology, Hospital General Universitario de Valencia, Valencia, Spain \\ ${ }^{3}$ Medical Department, Pfizer Inc. Europe, Alcobendas (Madrid), Spain \\ ${ }^{4}$ Medical Unit, Pfizer, S.L.U., Alcobendas (Madrid), Spain \\ Email: isabel.lizarraga@pfizer.com
}

Received 6 April 2016; accepted 11 June 2016; published 14 June 2016

Copyright (C) 2016 by authors and Scientific Research Publishing Inc.

This work is licensed under the Creative Commons Attribution International License (CC BY).

http://creativecommons.org/licenses/by/4.0/

(c) () Open Access

\begin{abstract}
Aim: To explore in daily clinical practice the evolution in time of the fesoterodine and solifenacin dose pattern and assess the therapeutic benefit provided by the highest dose of these anti-muscarinics. Patients and Methods: This was a post-hoc analysis of data from an observational, crosssectional, retrospective and multicenter study. Adult patients diagnosed with over active bladder $(O A B)$ who initiated fesoterodine or solifenacin treatment were included. Data on the prescribed treatment and dose, change of dose, reasons for switching and treatment benefit were recorded. Results: A total of 828 subjects were analyzed (262 receiving solifenacin and 566 fesoterodine). Most subjects were women with a mean time since diagnosis of more than one year and aged around 60 years old. The majority of patients initiated the OAB treatment with the lowest available dose (64\% fesoterodine vs. $77 \%$ solifenacin). At the follow-up visit $54 \%$ of the fesoterodine group and $66 \%$ of the solifenacin opted for dose escalation. At the study visit, $70.1 \%$ fesoterodine vs. $43.3 \%$ solifenacin remained on the highest dose. A significantly greater proportion of subjects receiving fesoterodine $8 \mathrm{mg}$, reported higher improvement in terms of both patient-reportedtreatment benefit and clinical global impression compared with solifenacin $10 \mathrm{mg}(\mathrm{p}<0.05)$. Conclusion: In routine clinical practice more than half of the patients opted for the higher dose and remained on it over time, suggesting a desire for greater efficacy. Fesoterodine $8 \mathrm{mg}$ seems to provide greater benefits from the physician's and the patient's point of view compared with those provided by solifenacin $10 \mathrm{mg}$.
\end{abstract}

*Corresponding author.

How to cite this paper: García-Mediero, J.M., Sánchez-Ballester, F., Arumi, D. and Lizarraga, I. (2016) Dose Pattern Evolution and Therapeutic Benefit in Patients on Solifenacin or Fesoterodine Treatment in Daily Clinical Practice. Open Journal of Urology, 6, 91-101. http://dx.doi.org/10.4236/oju.2016.66017 
Keywords

\section{Fesoterodine, Flexible-Dose, Overactive Bladder, Solifenacin}

\section{Introduction}

Overactive bladder (OAB) is a lower urinary tract disorder characterized by urgency with or without urge incontinence, often with increased daytime frequency and nocturia [1]. The symptoms associated with OAB can significantly affect the psychological, social, occupational, domestic, and sexual aspects of those who suffer from it [2]. As a result, OAB has a negative impact on the patient's quality of life [3]. Although antimuscarinic agents are the pharmacological mainstay of OAB treatment [4], efficacy and tolerability vary considerably among patients and agents [5] [6]. Drug sensitivity varies between patients due to a combination of pharmacodynamic and pharmacokinetic factors [7] [8]. Several antimuscarinics are available in more than one dose. Flexible dosing offers patients the option of increasing or decreasing their dose and thus optimizes the balance between efficacy and tolerability [9] [10]. Data from the EIGTH study provide confirmation that fesoterodine $8 \mathrm{mg}$ demonstrates superior efficacy compared with fesoterodine $4 \mathrm{mg}$ [11]. Notably, solid evidence of increased efficacy with higher approved doses has not been shown with other agents used in the treatment of OAB [12] [13] or has only been demonstrated over a short (4-week) period [11] [14].

Starting at the lowest available dose will allow identification of those patients who are responders and achieved a good efficacy-to-tolerability ratio with the lowest dose. However, patients with low-drug response may discontinue treatment due to a lack of efficacy. The perception of lack of efficacy is one of the most common reasons for non-compliance and discontinuation of OAB therapies [15] [16]. Some physicians prefer to start patients on a high dose and de-escalate if bothersome adverse events are noted [17] in order to prevent discontinuation or loss of confidence in the treatment. In observational and flexible-dose studies approximately $50 \%-63 \%$ of the subjects opted for dose escalation [6] [18].

This post-hoc analysis was aimed to explore in daily clinical practice the evolution in time of the fesoterodine and solifenacin dose pattern. In addition, the therapeutic benefit provided by the highest dose of these antimuscarinics was also assessed.

\section{Patients and Methods}

This was a post-hoc analysis of data from an observational, cross-sectional, retrospective, multicenter study, carried out by one hundred urologists and gynecologists at eighty-eight public and private centers from all over the Spain, and aimed at describing the profile of the overactive bladder (OAB) patient on treatment with flexible-dose antimuscarinic treatment in daily clinical practice. This was a non-interventional study, the choice of antimuscarinic and dose was at the discretion of the physicians in routine clinical practice. Eligible men and women were $\geq 18$ years of age, diagnosed with $\mathrm{OAB}$ who had initiated fesoterodine or solifenacin treatment and who made done two previous visits [starting treatment (v-2) and follow-up visits (v-1)] to the study visit (v0), with a period of time of at least of 8 weeks between the follow-up visit and the study visit. Patients undergoing inferior urinary tract surgery or who had given birth in the last year were excluded.

All patients provided their informed written consent. In accordance with the Spanish recommendations, the study was approved by the Clinical Research Ethics Committee of Hospital General Universitario of Valencia, and it was conducted in compliance with the principles contained in the Declaration of Helsinki for studies in humans.

Data from the visit in which the treatment was initiated (v-2) and from the follow-up visit (v-1) in which the dose could be adjusted were recorded retrospectively at the single study visit (v0).

Data on the prescribed treatment and dose, change of dose and reasons for switching during the follow-up, were recorded retrospectively from clinical records.

Patients also completed at the study visit several validated OAB-specific questionnaires including the overactive bladder questionnaire short form (OAB-q SF) [19], the patient perception of bladder condition (PPBC) [20] and the urgency perception scale (UPS) [21]. In addition they completed the treatment benefit scale (TBS) [22], the clinical global impression (CGI) scale [23], and the Morisky-Green scale [24]. 
$O A B q$ questionnaire asks about how much the patients have been bothered by selected bladder symptoms and how these symptoms have affected their life during the past 4 weeks. It comprises an eight-item Symptom Bother scale $(0=$ no bother to $100=$ maximum bother) and 25-item health-related quality of life (HRQL) scale with 4 domains ( $0=$ the worst HRQL to $100=$ the best HRQL). PPBC is a single-item, 6-point scale used that asks patients to rate the severity of their bladder-related problems (from $1=$ no-problems to $6=$ many severe problems). UPS is a three-point scale that assesses patient perception with regard to the urgency symptom. The CGI consists of two subscales. The first subscale, severity of illness (CGI-S), assesses the clinician's impression of the patient's current illness state; it is scored from $1=$ normal/not at all ill to $7=$ extremely ill. The Clinical Global Impression of improvement subscale (CGI-I), assesses the patient's improvement or worsening compared with the state before starting treatment, rating 1 - 7 ( 1 = very much improved, $7=$ very much worse $)$. The TBS is a self-administered single-item instrument used to compare the current state of their urinary problems with their state before the start of the treatment. Rating 1 - 4 (1 = greatly improved, $4=$ worsened during the treatment). The Morisky-Green questionnaire is a four-question survey to assess the patient's treatment adherence. Patients were classified as compliant when they answered correctly the 4 questions [24].

\section{Statistical Methods}

In this post-hoc analysis, patients were stratified according to treatment and whether they opted at the follow-up visit for maintaining the highest dose initially prescribed or for dose escalation.

To carry out this post-hoc analysis, a statistical power of the study was previously calculated, which would allow to assure, with an error $\alpha<0.05$ and an error $\beta<0.2$, that with the sample size recruited, was available a sufficient statistical power to perform separate bilateral contrasts between fesoterodine and solifenacin, both in the dose maintenance group and in the dose escalation group. The score on "Bother by OAB symptoms" from OABs-SF questionnaire was used to calculate previously the statistical power, as this variable was the most approximate one available in the study that assessed, from the patient's point of view, the degree of discomfort of the OAB symptoms, since no mictional diary was available that could measure the number of urinary urgencies with or without incontinence, characteristic of the OAB, but which are not used on a routine basis in daily clinical practice. The statistical power detected for this variable was $82.1 \%$ in the comparison of the dose maintenance groups and $81.2 \%$ in the escalation one.

The patient's degree of improvement or worsening according to the CGI-I subscale was categorized as improved (very much improved, much improved, minimally improved), no change or impaired (minimally worse, much worse, very much worse). The current state of the patient's urinary problems compared with the state before the start of the study, according to the TBS, was also grouped into three categories: improved (greatly improved, improved) no change or impaired (worsened during the treatment).

A descriptive statistical analysis of all the variables was performed, including central tendency and dispersion measures for continuous variables, and absolute and relative frequencies for categorical variables. Student's t-test, Mann-Whitney-U test or Kruskall Wallis H test were used to compare quantitative variables and Pearson's chi-square or Fisher exact tests for qualitative variables. Tests were two-tailed with a significance level of 5\%. Data were analyzed using SPSS V17.0 statistical software.

\section{Results}

A total of 851 patients were included in the original study of which 828 subjects were analyzed in this post-hoc study (262 receiving solifenacin and 566 fesoterodine).

Demographic and clinical characteristics of the patients were similar amongst treatment groups (Table 1). Most subjects were women with a mean time since diagnosis of more than one year and aged around 60 years old. The majority of patients suffered from at least one concomitant disease, the most frequent being hypertension (Table 1). The majority of the patients were receiving concomitant medications (76.8\% - 66.7\%) (Table 2). The only difference observed between groups was that a significantly greater proportion of men in the escalator fesoterodine group received concomitantly alpha-blockers compared with the solifenacin group (0.047).

Treatment length was significantly shorter in fesoterodine groups compared with solifenacin [mean (SD) in patients who maintained the highest dose: $(n=156) 10.2(10.8)$ weeks fesoterodine vs. $(n=48) 21.3(27.9)$ weeks solifenacin $(p=0.001)$; escalators: $(n=194) 16.7(18.6)$ weeks fesoterodine vs. $(n=134) 17.5(14.5)$ weeks solifenacin $(\mathrm{p}=0.011)]$. 
Table 1. Demographic and clinical characteristics.

\begin{tabular}{|c|c|c|c|c|c|c|}
\hline & \multicolumn{2}{|c|}{$\begin{array}{l}\text { Maintaining higher dose } \\
\text { at follow-up visit }\end{array}$} & \multicolumn{4}{|c|}{$\begin{array}{l}\text { Dose escalation } \\
\text { at follow-up visit }\end{array}$} \\
\hline & $\begin{array}{c}\text { Fesoterodine } \\
156\end{array}$ & $\begin{array}{l}\text { Solifenacin } \\
\quad 48\end{array}$ & $p$ value & $\begin{array}{c}\text { Fesoterodine } \\
194\end{array}$ & $\begin{array}{c}\text { Solifenacin } \\
134\end{array}$ & p value \\
\hline Women, n (\%) & $235(86.5)$ & $40(83.3)$ & NS & $144(74.2)$ & $98(73.1)$ & NS \\
\hline Age, mean (SD), years & $62.2(12.3)$ & $59.4(13.7)$ & NS & $61.4(10.8)$ & $60.8(12.5)$ & NS \\
\hline BMI, mean (SD), Kg/m² & $26.0(4.3)$ & $25.5(4.4)$ & NS & $26.5(3.6)$ & $26.1(3.7)$ & NS \\
\hline OAB evolution time, mean (SD), months & $14.5(22.2)$ & $17.9(21.8)$ & NS & $21.6(69.0)$ & $17.4(21.6)$ & NS \\
\hline Concomitant disease, mean (SD) & $2.9(2.6)$ & $2.9(2.5)$ & NS & $3.3(2.7)$ & $3.4(2.8)$ & NS \\
\hline Concomitant disease, $\mathrm{n}(\%)$ & $128(82.1)$ & $37(77.1)$ & NS & $170(87.6)$ & $113(84.3)$ & NS \\
\hline Hypertension & $63(49.2)$ & $11(29.7)$ & 0.040 & $85(50.0)$ & $64(56.6)$ & NS \\
\hline Cardiovascular disease & $20(15.6)$ & $6(11.1)$ & 0.008 & $13(7.6)$ & $18(15.9)$ & 0.033 \\
\hline Urinary tract infections & $62(48.4)$ & $16(43.2)$ & NS & 77 (45.3) & $32(28.3)$ & 0.004 \\
\hline Mellitus diabetes & 25 (19.5) & $7(18.9)$ & NS & 32(18.8) & 21 (18.5) & NS \\
\hline Depression & $35(27.3)$ & $9(24.3)$ & NS & $38(22.3)$ & $28(24.7)$ & NS \\
\hline Insomnia & $42(32.8)$ & $12(32.4)$ & NS & $50(29.4)$ & $49(43.4)$ & 0.016 \\
\hline Obesity (BMI $\geq 30 \mathrm{Kg} / \mathrm{m}^{2}$ ) & $29(22.7)$ & $6(16.2)$ & NS & $42(24.7)$ & $26(23.0)$ & NS \\
\hline Rheumatic disease & $18(14.1)$ & $9(24.3)$ & NS & $36(21.2)$ & $28(24.8)$ & NS \\
\hline Fibromyalgia & $2(1.6)$ & $3(8.1)$ & NS & $15(8.8)$ & $21(18.6)$ & 0.018 \\
\hline${ }^{*} \mathrm{BPH}$ & $16 / 21(76.2)$ & 3/8 (37.5) & NS & $33 / 50(66.0)$ & 21/36 (58.3) & NS \\
\hline
\end{tabular}

NS: p value non significant (p > 0.05); BMI: Body Mass Index; OAB: Overactive bladder; VH: Vejiga hiperactiva; HTA: Hipertensión; DM: Diabetes Mellitus; HBP: Hiperplasiabenigna de prostate; ${ }^{*} \mathrm{BPH}$ : Benign prostatic hyperplasia (n/N) percentage with regard to the total number of men.

Table 2. Main concomitant treatments.

\begin{tabular}{|c|c|c|c|c|c|c|}
\hline & \multicolumn{2}{|c|}{$\begin{array}{l}\text { Maintaining higher dose } \\
\text { at follow-up visit }\end{array}$} & \multicolumn{4}{|c|}{$\begin{array}{l}\text { Dose escalation } \\
\text { at follow-up visit }\end{array}$} \\
\hline & $\begin{array}{c}\text { Fesoterodine } \\
156\end{array}$ & $\begin{array}{c}\text { Solifenacin } \\
48\end{array}$ & p value & $\begin{array}{c}\text { Fesoterodine } \\
194\end{array}$ & $\begin{array}{c}\text { Solifenacin } \\
134\end{array}$ & p value \\
\hline Concomitant treatment, mean (SD) & $2.4(1.8)$ & $2.5(1.8)$ & NS & $2.1(1.3)$ & $2.4(1.4)$ & NS \\
\hline Concomitant treatment, n (\%) & $118(75.6)$ & $32(66.7)$ & NS & $149(76.8)$ & $100(74.6)$ & NS \\
\hline NASID & $43(36.4)$ & $14(43.8)$ & NS & $51(34.2)$ & $42(42.0)$ & NS \\
\hline ACE inhibitors & $25(21.2)$ & $6(18.8)$ & NS & 29 (19.5) & $26(26.0)$ & NS \\
\hline "Uroselectivealpha1-blocker & 6/21 (28.5) & $2 / 8(25.0)$ & NS & $23 / 50(46.0)$ & $9 / 36(25.0)$ & 0.047 \\
\hline Antibiotics for UTI & $16(13.6)$ & $5(15.6)$ & NS & $26(17.4)$ & $9(9.0)$ & NS \\
\hline Hypnotics & $16(13.6)$ & $6(18.8)$ & NS & 19 (12.8) & $17(17.0)$ & NS \\
\hline SSRIs & $13(11.0)$ & 7 (21.9) & NS & 19 (12.8) & $13(13.0)$ & NS \\
\hline
\end{tabular}

NSAIDs: Nonsteroidal anti-inflammatory drugs; ACE inhibitor: Angiotensin-converting-enzyme inhibitor; UTI: Urinary tract infections; SSRIs: Selective serotonin reuptake inhibitors. "Regarding to the total number of men.

Subject disposition at the different visits of the study according to treatment and dose is shown in Figure 1. The most of patients initiated the OAB treatment with the lowest available dose, (64\% fesoterodine vs. $77 \%$ solifenacin). At the follow-up visit the $54 \%$ and $66 \%$ of the fesoterodine and solifenacin patients respectively opted for dose escalation, whereas only around $20 \%$ decided to decrease the dose (Figure 1). At the study visit, the proportion of patients who maintained the initial dose prescribed was greater in the fesoterodine group compared with solifenacin $(70.1 \%(143 / 204)$ vs. $43.3 \%$ (26/60) remained on the highest dose; 38.6\% (140/362) 


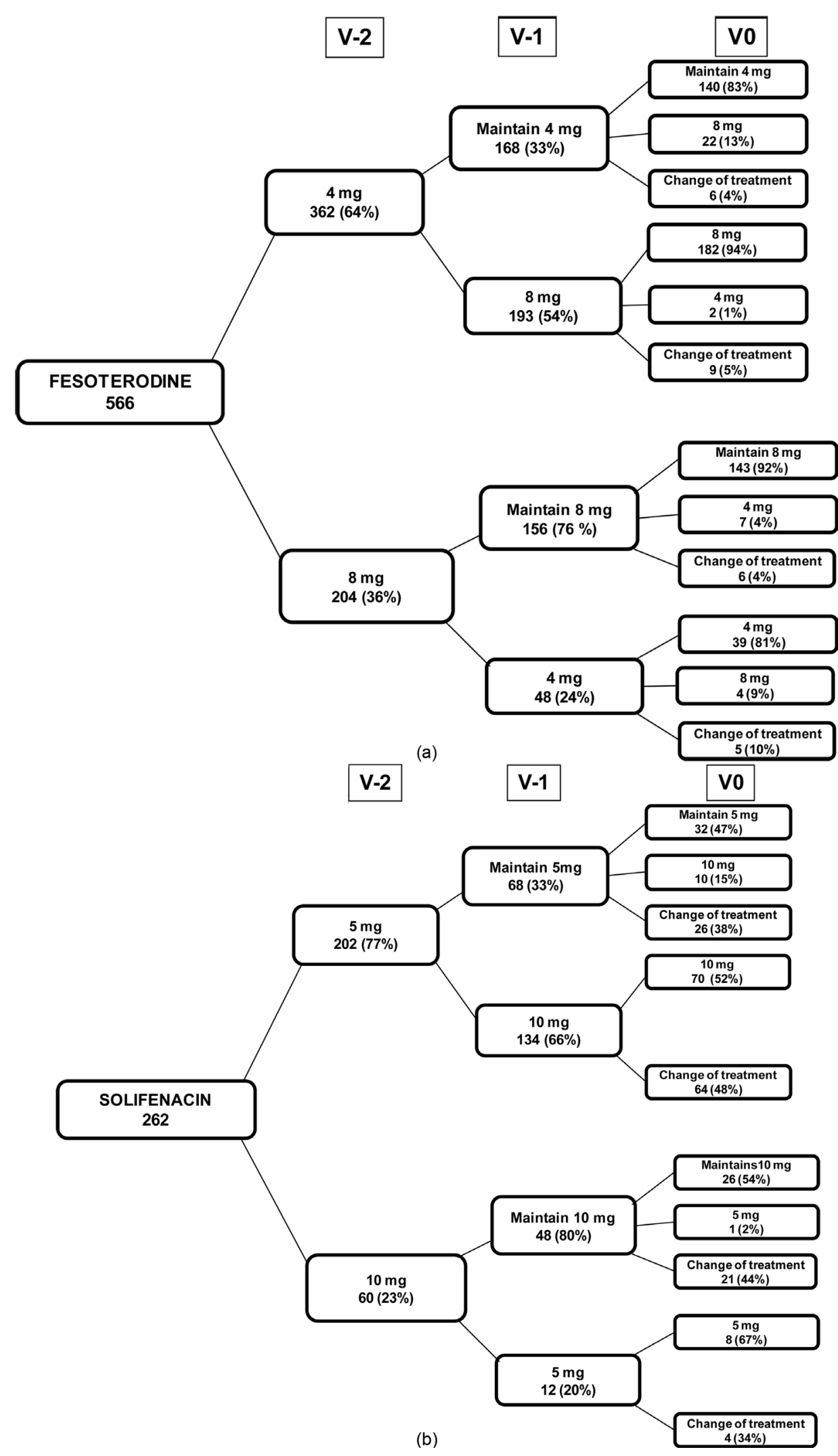

Figure 1. Subject disposition during the study according to treatment and dose. (a) Fesoterodine; (b) Solifenacin. v-2: starting treatment visit; v-1: follow-up visit; v0: study visit. 
vs. $15.8 \%$ (32/202) remained on the lowest dose). The reasons for switching dose at follow-up visit were mainly due to lack of effectiveness ( $74.7 \%$ fesoterodine vs. $80.8 \%$ solifenacin), followed by side effects $(15.0 \%$ fesoterodine vs. $8.3 \%$ solifencin). Similarly, at the study visit, lack of effectiveness also led to switching in most of the cases (45.7\% fesoterodine vs. $67.3 \%$ solifenacin), followed by side effects ( $28.6 \%$ fesoterodine vs. $18.8 \%$ solifenacin).

Figure 2 shows the overall count of all patients who received the same dose at each visit with regard to the initial number of patients on each treatment. At the follow-up visit a higher use of high dose was observed in the solifenacin group (61.5\% fesoterodine, $69.5 \%$ solifenacin, $\mathrm{p}=0.029$ ), however, at the study visit, the proportion of patients who received the higher dose was greater in the fesoterodine group compared with solifenacin (62.0\% vs. $40.5 \%, \mathrm{p}=0.0001)$. One hundred and fifteen $(43.9 \%)$ patients of the solifenacin group required switching of treatment at study visit vs. 26 (4.6\%) patients that received fesoterodine.

Table 3 shows the OAB clinical assessment at study visit. The illness status of patients in the physician's judgement was meaningfully better in the fesoterodine groups according to CGI-S (Table 3). Furthermore from the physician's point of view (CGI-I), the treatment benefit achieved in the fesoterodine groups was significantly better compared with the solifenacin groups (Table 3). The proportion of patients who improved according to CGI-I (categorized as improved: very much improved, much improved, minimally improved) was meaning fully higher in the escalator fesoterodine group than in the escalator solifenacin group $(91.0 \%$ vs. $77.1 \%, p=0.002)$; however, between the treatment groups of patients who maintained the highest dose, numerical but no significant differences were observed (94.3\% fesoterodine vs. $88.1 \%$ solifenacine, $\mathrm{p}=0.097)$. Patient-reported treatment benefit (TBS), was also significantly higher in the fesoterodine groups compared with solifenacin (Table $3)$. Patients who received fesoterodine, reported having significantly less bother due to bladder symptoms and lower severity of their bladder-related problems according to OAB-q and PPBC questionnaires (Table 3). However, scores on the UPS scale indicated a similar perception of the urgency symptom in both treatment groups (Table 3). The treatment compliance rate was similar between treatment groups (Table 3). With regard to the use of healthcare resources, a significantly greater reduction was only observed in the number of absorbents used in the fesoterodine group that maintained the highest dose compared with solifenacin, but not between groups that increased the dose (Table 3).

\section{Discussion}

This post-hoc analysis provides real-world data on dose patterns of the two novel anticholinergics agents.

In the present study most of the patients initiated the OAB treatment with the lowest available dose, as is recommended. At the follow-up visit, however, more than half opted for dose escalation, whereas only around $20 \%$ of those who initiated with the highest dose decided to decrease it. Our findings, stemming from the usual clinical practice, were in line with those reported in previous flexible-dose trials [6] [25]-[30].

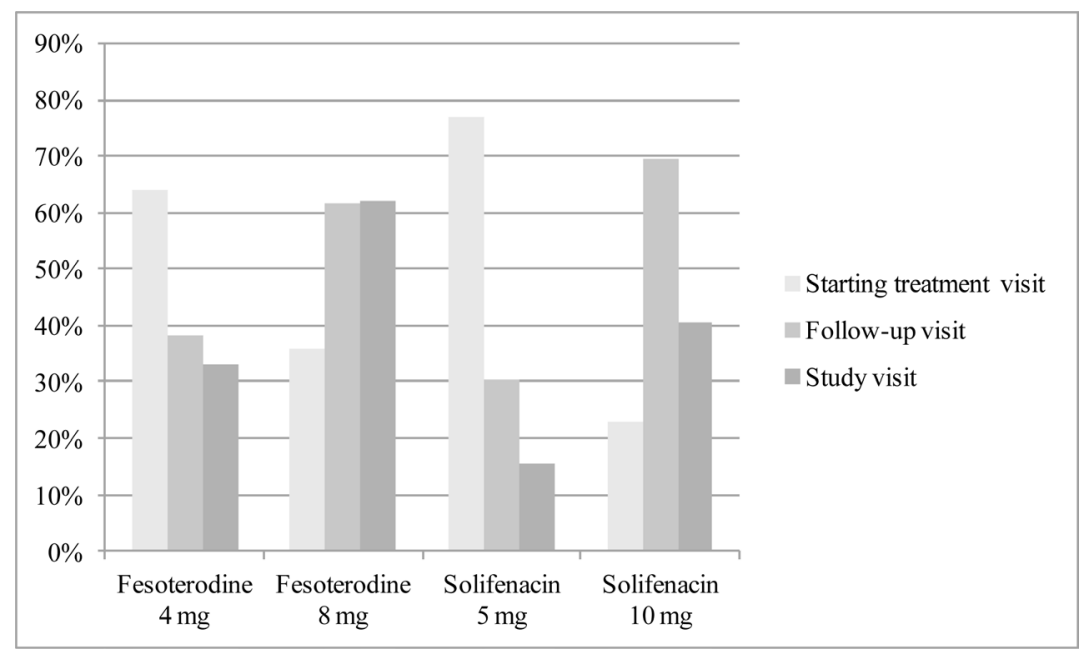

Figure 2. Overall dose evolution during the study. Overall count of all patients who received the same dose at each visit with regard to the initial number of patients on each treatment. 
Table 3. OAB clinical assessment and healthcare resources at study visit.

\begin{tabular}{|c|c|c|c|c|c|c|}
\hline & \multicolumn{2}{|c|}{$\begin{array}{l}\text { Maintaining higher dose } \\
\text { at follow-up visit }\end{array}$} & \multicolumn{4}{|c|}{$\begin{array}{l}\text { Dose escalation } \\
\text { at follow-up visit }\end{array}$} \\
\hline & $\begin{array}{l}\text { Fesoterodine } \\
\quad 156\end{array}$ & $\begin{array}{c}\text { Solifenacin } \\
\quad 48\end{array}$ & p value & $\begin{array}{c}\text { Fesoterodine } \\
194\end{array}$ & $\begin{array}{l}\text { Solifenacin } \\
\qquad 134\end{array}$ & $p$ value \\
\hline ICG-S, mean (SD) & $2.2(1.2)$ & $2.9(1.3)$ & 0.002 & $2.7(1.4)$ & $3.1(1.2)$ & 0.002 \\
\hline ICG-I, mean (SD) & $1.9(1.0)$ & $2.3(1.2)$ & 0.040 & $2.0(0.9)$ & $2.4(1.0)$ & $<0.001$ \\
\hline TBS, n (\%) & & & 0.015 & & & 0.002 \\
\hline Improved & $143(91.6)$ & $37(77.1)$ & & $177(91.2)$ & $112(83.5)$ & \\
\hline No change & $11(7.1)$ & $10(20.8)$ & & $17(8.8)$ & $21(15.7)$ & \\
\hline Impaired & $2(1.3)$ & $1(2.1)$ & & $0(0.0)$ & $1(0.7)$ & \\
\hline \multicolumn{7}{|l|}{ OAB-q, mean (SD) } \\
\hline Symptom bother & $26.8(18.4)$ & $36.1(22.7)$ & 0.014 & $32.4(20.2)$ & $38.9(20.4)$ & 0.003 \\
\hline Total HRQL & 75. 4 (17.7) & 67.5 (20.6) & 0.027 & $70.2(18.9)$ & $66.3(19.7)$ & NS \\
\hline PPBC, mean (SD) & $1.7(1.2)$ & $2.2(1.3)$ & 0.041 & $2.1(1.2)$ & $2.4(1.1)$ & 0.017 \\
\hline UPS, n (\%) & & & NS & & & NS \\
\hline Not able to hold urine & $19(12.2)$ & $11(22.9)$ & & $36(18.6)$ & $33(24.6)$ & \\
\hline $\begin{array}{l}\text { Able to hold urine until I reach the toilet } \\
\text { if I go immediately }\end{array}$ & $78(50.0)$ & $26(54.2)$ & & $112(57.7)$ & $78(58.2)$ & \\
\hline $\begin{array}{l}\text { Able to finish what I am doing before } \\
\text { going to the toilet }\end{array}$ & $59(37.8)$ & $11(22.9)$ & & $46(23.7)$ & $23(17.2)$ & \\
\hline Morisky-Green, compliant, n (\%) & $97(62.2)$ & $24(50.0)$ & NS & $88(45.4)$ & $59(44.0)$ & NS \\
\hline \multicolumn{7}{|l|}{ Healthcare resources, mean (SD) } \\
\hline${ }^{*}$ Absorbent reduction & -1.2 & -0.5 & 0.011 & -1.4 & -1.2 & NS \\
\hline Primary care visits & $1.8(3.1)$ & $2.3(2.9)$ & NS & $2.4(2.8)$ & $2.4(3.5)$ & NS \\
\hline Specialist visits & $2.4(1.6)$ & $3.4(3.0)$ & NS & $2.6(1.8)$ & $3.4(3.7)$ & NS \\
\hline
\end{tabular}

OAB-q: Overactive Bladder Questionnaire short form; HRQL: Health related quality of life; PPBC: Patient perception of bladder condition; UPS: Urgency perception scale; CGI-I: Clinical global impression of improvement; CGI-s: Clinical global impression of severity; TBS: Treatment benefit scale; "absorbent used v0 - v-1.

The availability of different doses provides an opportunity to establish an optimal balance between efficacy and tolerability in individual patients [9] [10]. Subjects with high drug sensitivity may experience sufficient efficacy on a lower dose of drug but experience unacceptable tolerability on a higher dose. In contrast, subjects with low drug sensitivity may experience insufficient efficacy on a lower dose but experience increased benefit with acceptable tolerability on a higher dose [7] [25]. The results of the present study seem to indicate that in routine clinical practice a large proportion of patients could belong to the latter group of subjects.

The usual approach is to start off at the lowest available dose and escalate to a higher dose when needed [7]. Some physicians, however, prefer to start patients on a high dose and de-escalate if bothersome AEs are noted [17] due to lack of efficacy is one of the most common reasons for non-compliance and discontinuation with $\mathrm{OAB}$ therapies [15] [16]. Furthermore, some patients need a more rapid symptom reduction, so starting on high dose could be justified in cases of severe OAB [9], previous treatment failure [17] or when OAB symptoms have a significant impact on the patient's psychosocial environment [31]. These patients need a positive reinforcement that prevents discontinuation or loss of confidence in the treatment.

In this study lack of effectiveness led to switching dose in most of the cases. Collectively, these data may suggest, such as was reported by other authors [18], that efficacy concerns may contribute more to the decision to increase the dose than tolerability concerns.

In the present study, the proportion of patients who remained on the initial dose prescribed to the end of the study was greater in the fesoterodine group compared with solifenacin $(70.1 \%$ vs. $43.3 \%$ remained on the high- 
est dose; $38.6 \%$ vs. $15.8 \%$ remained on the lowest dose). A recent observational, multicenter and retrospective study aimed at assessing persistence in patients initiating treatment with fesoterodine, solifenacin or tolterodine in routine clinical practice showed that the cumulative probability of remaining on initial antimuscaric at 52 week was significantly higher for fesoterodine than for solifenacin and tolterodine [32]. Compared with fesoterodine, the proportion of patients who required switching of treatment at study visit was higher in the solifenacin group. Although we should be borne in mind the lack of homogeneity on treatment duration between groups, our results would be in line with data of the study stated above. In addition, the proportion of patients who remained on fesoterodine $8 \mathrm{mg}$ was similar to those described in a long-term open-label extension trial, where $61 \%$ of the patients continued fesoterodine treatment for $\geq 24$ months and $71 \%$ elected to maintain the fesoterodine 8-mg dose throughout treatment [33].

Efficacy and tolerability of the different antimuscarinics vary due to pharmacokinetic and pharmacodynamic properties [34] [35]. The utility of multiple doses is based on the assumption of a dose-response effect. The clearly dose-response provided by fesoterodine has been shown in several clinical trials and in routine medical practice [6] [11] [25] [36]. Several studies of solifenacin flexible-dose have been carried out, but direct comparison data between non-escalator and escalator patients have not been finally published [29] [37]. Recently, improved effectiveness with up-titration has been shown for solifenacin in a randomized clinical trial [38]. Chun et $a l$. in a observational retrospective study aimed to determine the baseline clinical characteristics associated with dose escalation of solifenacin in OAB patients, showed, in contrast to the week 4 results, no significant differences in the diary variables (mean numbers of micturitions, urgency episodes and IUU episodes per 24 hours) between escalator and non-escalator groups after 12 and 24 weeks on treatment [39]. Recently, have been published a observational study which primary objective was to evaluate the efficacy and safety of flexible dose solifenacin in men with LUTS, but comparative data between solifenacin $10 \mathrm{mg}$ vs. $5 \mathrm{mg}$ were not shown [40].

Our findings seem to be in line with those reported previously [41]. In the present study, the majority of the patients reported being improved, however a significantly greater proportion of subjects receiving fesoterodine 8 $\mathrm{mg}$, reported greater improvement in terms of both patient-reported-treatment benefit and clinical global impression compared with solifenacin $10 \mathrm{mg}$. In addition, although should be borne in mind that the basal OAB severity of the patients was not recorded, overall patients who received fesoterodine stated a significantly better OAB perception of their bladder condition according to OAB-q and PPBC questionnaires compared with solifenacin.

The results of the present study should be interpreted within the context of its limitations. There were limitations inherent in the observational design of the study. In this study, the groups of patients were well-balanced, yet, as was stated above, the treatment length differed between groups. In addition, some baseline data such as the basal $\mathrm{OAB}$ severity of the patients, were not registered due to the retrospective and cross-sectional nature of the design of the study.

\section{Conclusion}

In conclusion, our analysis suggests that in routine clinical practice more than half of the patients opted for the higher dose and remained on it over time, suggesting the need for greater efficacy, while a smaller proportion of patients seem to achieve a favorable balance of efficacy and tolerability with a lower dose. Moreover, fesoterodine $8 \mathrm{mg}$ seems to provide greater benefits from the physician's and the patient's point of view compared with those provided by solifenacin $10 \mathrm{mg}$.

\section{References}

[1] Abrams, P., Artibani, W., Cardozo, L., Dmochowski, R., Van, K.P. and Sand, P. (2009) Reviewing the ICS 2002 Terminology Report: The Ongoing Debate. Neurourology and Urodynamics, 28, 287. http://dx.doi.org/10.1002/nau.20737

[2] Abrams, P., Kelleher, C.J., Kerr, L.A. and Rogers, R.G. (2000) Overactive Bladder Significantly Affects Quality of Life. American Journal of Managed Care, 6, S580-S590.

[3] Coyne, K.S., Payne, C., Bhattacharyya, S.K., Revicki, D.A., Thompson, C., Corey, R. and Hunt, T.L. (2004) The Impact of Urinary Urgency and Frequency on Health-Related Quality of Life in Overactive Bladder: Results from a National Community Survey. Value Health, 7, 455-463. http://dx.doi.org/10.1111/j.1524-4733.2004.74008.x

[4] Ouslander, J.G. (2004) Management of Overactive Bladder. New England Journal of Medicine, 350, 786-799. http://dx.doi.org/10.1056/NEJMra032662

[5] Chapple, C.R., Khullar, V., Gabriel, Z., Muston, D., Bitoun, C.E. and Weinstein, D. (2008) The Effects of Antimusca- 
rinic Treatments in Overactive Bladder: An Update of a Systematic Review and Meta-Analysis. European Urology, 54, 543-562. http://dx.doi.org/10.1016/j.eururo.2008.06.047

[6] Wyndaele, J.J., Goldfischer, E.R., Morrow, J.D., Gong, J., Tseng, L.J., Guan, Z. and Choo, M.S. (2009) Effects of Flexible-Dose Fesoterodine on Overactive Bladder Symptoms and Treatment Satisfaction: An Open-Label Study. International Journal of Clinical Practice, 63, 560-567. http://dx.doi.org/10.1111/j.1742-1241.2009.02035.x

[7] Michel, M.C. and Staskin, D. (2011) Understanding Dose Titration: Overactive Bladder Treatment with Fesoterodine as an Example. European Urology Supplements, 10, 8-13. http://dx.doi.org/10.1016/j.eursup.2011.01.004

[8] Oefelein, M.G. (2011) Safety and Tolerability Profiles of Anticholinergic Agents Used For the Treatment of Overactive Bladder. Drug Safety, 34, 733-754. http://dx.doi.org/10.2165/11592790-000000000-00000

[9] Chapple, C.R., Rosenberg, M.T. and Brenes, F.J. (2009) Listening to the Patient: A Flexible Approach to the Use of Antimuscarinic Agents in Overactive Bladder Syndrome. BJU International, 104, 960-967. http://dx.doi.org/10.1111/j.1464-410X.2009.08545.x

[10] Staskin, D., Khullar, V., Michel, M.C., Morrow, J.D., Sun, F., Guan, Z. and Dmochowski, R. (2011) Effects of Voluntary Dose Escalation in a Placebo-Controlled, Flexible-Dose Trial of Fesoterodine in Subjects with Overactive Bladder. Neurourology and Urodynamics, 30, 1480-1485. http://dx.doi.org/10.1002/nau.21099

[11] Chapple, C., Schneider, T., Haab, F., Sun, F., Whelan, L., Scholfield, D., Dragon, E. and Mangan, E. (2014) Superiority of Fesoterodine $8 \mathrm{mg}$ vs $4 \mathrm{mg}$ in Reducing Urgency Urinary Incontinence Episodes in Patients with Overactive Bladder: Results of the Randomised, Double-Blind, Placebo-Controlled EIGHT Trial. BJU International, 114, 418426. http://dx.doi.org/10.1111/bju.12678

[12] Hill, S., Khullar, V., Wyndaele, J.J. and Lheritier, K. (2006) Dose Response with Darifenacin, a Novel Once-Daily M3 Selective Receptor Antagonist for the Treatment of Overactive Bladder: Results of a Fixed Dose Study. International Urogynecology Journal and Pelvic Floor Dysfunction, 17, 239-247. http://dx.doi.org/10.1007/s00192-005-1340-3

[13] Cardozo, L., Lisec, M., Millard, R., van Vierssen, T.O., Kuzmin, I., Drogendijk, T.E., Huang, M. and Ridder, A.M. (2004) Randomized, Double-Blind Placebo Controlled Trial of the Once Daily Antimuscarinic Agent Solifenacin Succinate in Patients with Overactive Bladder. Journal of Urology, 172, 1919-1924. http://dx.doi.org/10.1097/01.ju.0000140729.07840.16

[14] Corcos, J., Casey, R., Patrick, A.., Andreou, C., Miceli, P.C., Reiz, J.L., Harsanyi, Z. and Darke, A.C. (2006) A Double-Blind Randomized Dose-Response Study Comparing Daily Doses of 5, 10 and $15 \mathrm{mg}$ Controlled-Release Oxybutynin: Balancing Efficacy with Severity of Dry Mouth. BJU International, 97, 520-527. http://dx.doi.org/10.1111/j.1464-410X.2005.06031.x

[15] Castro, D., Miranda, P., Sanchez-Ballester, F., Arumi, D., Lizarraga, I. and Ebel, C. (2011) Assessment of Reasons for Overactive Bladder Treatment Change. Actas Urológicas Españolas, 35, 73-79. http://dx.doi.org/10.1016/s2173-5786(11)70022-1

[16] Benner, J.S., Nichol, M.B., Rovner, E.S., Jumadilova, Z., Alvir, J., Hussein, M., Fanning, K., Trocio, J.N. and Brubaker, L. (2010) Patient-Reported Reasons for Discontinuing Overactive Bladder Medication. BJU International, 105, 1276-1282. http://dx.doi.org/10.1111/j.1464-410X.2009.09036.x

[17] Garcia-Baquero, R., Madurga, B., Garcia, M.V., Fernandez, M.A., Rosety, J.M. and Alvarez-Ossorio, J.L. (2013) New Perspectives of Treatment with Fesoterodine Fumarate in Patients with Overactive Bladder. Actas Urológicas Españolas (English Edition), 37, 83-91. http://dx.doi.org/10.1016/j.acuroe.2012.05.016

[18] Cardozo, L., Hall, T., Ryan, J., Ebel, B.C., Kausar, I., Darekar, A. and Wagg, A. (2012) Safety and Efficacy of Flexible-Dose Fesoterodine in British Subjects with Overactive Bladder: Insights into Factors Associated with Dose Escalation. International Urogynecology Journal, 23, 1581-1590. http://dx.doi.org/10.1007/s00192-012-1804-1

[19] Coyne, K., Revicki, D., Hunt, T., Corey, R., Stewart, W., Bentkover, J., Kurth, H. and Abrams, P. (2002) Psychometric Validation of an Overactive Bladder Symptom and Health-Related Quality of Life Questionnaire: The OAB-q. Quality of Life Research, 11, 563-574. http://dx.doi.org/10.1023/A:1016370925601

[20] Coyne, K.S., Matza, L.S., Kopp, Z. and Abrams, P. (2006) The Validation of the Patient Perception of Bladder Condition (PPBC): A Single-Item Global Measure for Patients with Overactive Bladder. European Urology, 49, 1079-1086. http://dx.doi.org/10.1016/j.eururo.2006.01.007

[21] Cardozo, L., Coyne, K.S. and Versi, E. (2005) Validation of the Urgency Perception Scale. BJU International, 95, 591596. http://dx.doi.org/10.1111/j.1464-410X.2005.05345.X

[22] Colman, S., Chapple, C., Nitti, V., Haag-Molkenteller, C., Hastedt, C. and Massow, U. (2008) Validation of Treatment Benefit Scale for Assessing Subjective Outcomes in Treatment of Overactive Bladder. Urology, 72, 803-807. http://dx.doi.org/10.1016/j.urology.2008.05.033

[23] Guy, W. (1976) Clinical Global Impressions. In: Guy, W., Ed., ECDEU Assessment Manual for Psychopharmacology, 
Revised DHEW Publication (ADM), National Institute for Mental Health, Rockville, 218-222.

[24] Morisky, D.E., Green, L.W. and Levine, D.M. (1986) Concurrent and Predictive Validity of a Self-Reported Measure of Medication Adherence. Medical Care, 24, 67-74. http://dx.doi.org/10.1097/00005650-198601000-00007

[25] Wyndaele, J.J., Schneider, T., MacDiarmid, S., Scholfield, D. and Arumi, D. (2014) Flexible Dosing with Fesoterodine 4 and 8 mg: A Systematic Review of Data from Clinical Trials. International Journal of Clinical Practice, 68, 830-840. http://dx.doi.org/10.1111/ijcp.12425

[26] Weiss, J.P., Jumadilova, Z., Johnson, T.M., FitzGerald, M.P., Carlsson, M., Martire, D.L. and Malhotra, A. (2013) Efficacy and Safety of Flexible Dose Fesoterodine in Men and Women with Overactive Bladder Symptoms Including Nocturnal Urinary Urgency. The Journal of Urology, 189, 1396-1401. http://dx.doi.org/10.1016/j.juro.2012.11.067

[27] Dubeau, C.E., Kraus, S.R., Griebling, T.L., Newman, D.K., Wyman, J.F., Johnson, T.M., Ouslander, J.G., Sun, F., Gong, J. and Bavendam, T. (2014) Effect of Fesoterodine in Vulnerable Elderly Subjects with Urgency Incontinence: A Double-Blind, Placebo Controlled Trial. The Journal of Urology, 191, 395-404.

http://dx.doi.org/10.1016/j.juro.2013.08.027

[28] Chapple, C.R., Martinez-Garcia, R., Selvaggi, L., Toozs-Hobson, P., Warnack, W., Drogendijk, T., Wright, D.M. and Bolodeoku, J. (2005) A Comparison of the Efficacy and Tolerability of Solifenacin Succinate and Extended Release Tolterodine at Treating Overactive Bladder Syndrome: Results of the STAR Trial. European Urology, 48, 464-470. http://dx.doi.org/10.1016/j.eururo.2005.05.015

[29] Cardozo, L., Hessdorfer, E., Milani, R., Arano, P., Dewilde, L., Slack, M., Drogendijk, T., Wright, M. and Bolodeoku, J. (2008) Solifenacin in the Treatment of Urgency and Other Symptoms of Overactive Bladder: Results from a Randomized, Double-Blind, Placebo-Controlled, Rising-Dose Trial. BJU International, 102, 1120-1127. http://dx.doi.org/10.1111/j.1464-410x.2008.07939.x

[30] Karram, M.M., Toglia, M.R., Serels, S.R., Andoh, M., Fakhoury, A. and Forero-Schwanhaeuser, S. (2009) Treatment with Solifenacin Increases Warning Time and Improves Symptoms of Overactive Bladder: Results from VENUS, a Randomized, Double-Blind, Placebo-Controlled Trial. Urology, 73, 14-18.

http://dx.doi.org/10.1016/j.urology.2008.08.485

[31] Nicolson, P., Kopp, Z., Chapple, C.R. and Kelleher, C. (2008) It’s Just the Worry about Not Being Able to Control It! A Qualitative Study of Living with Overactive Bladder. British Journal of Health Psychology, 13, 343-359. http://dx.doi.org/10.1348/135910707X187786

[32] Sicras-Mainar, A., Rejas, J., Navarro-Artieda, R., Aguado-Jodar, A., Ruiz-Torrejon, A., Ibanez-Nolla, J. and Kvasz, M. (2014) Antimuscarinic Persistence Patterns in Newly Treated Patients with Overactive Bladder: A Retrospective Comparative Analysis. International Urogynecology Journal, 25, 485-492. http://dx.doi.org/10.1007/s00192-013-2250-4

[33] Van Kerrebroeck, P.E., Heesakkers, J., Berriman, S., Padmanabhan, A.L., Carlsson, M. and Guan, Z. (2010) LongTerm Safety, Tolerability and Efficacy of Fesoterodine Treatment in Subjects with Overactive Bladder Symptoms. International Journal of Clinical Practice, 64, 584-593. http://dx.doi.org/10.1111/j.1742-1241.2010.02361.x

[34] Doroshyenko, O. and Fuhr, U. (2009) Clinical Pharmacokinetics and Pharmacodynamics of Solifenacin. Clinical Pharmacokinetics, 48, 281-302. http://dx.doi.org/10.2165/00003088-200948050-00001

[35] Malhotra, B.K., Wood, N. and Sachse, R. (2009) Influence of Age, Gender, and Race on Pharmacokinetics, Pharmacodynamics, and Safety of Fesoterodine. International Journal of Clinical Pharmacology and Therapeutics, 47, 570578. http://dx.doi.org/10.5414/CPP47570

[36] Castro-Diaz, D., Miranda, P., Sanchez-Ballester, F., Lizarraga, I., Arumi, D. and Rejas, J. (2012) Dose and Aging Effect on Patients Reported Treatment Benefit Switching from the First Overactive Bladder Therapy with Tolterodine ER to Fesoterodine: Post-Hoc Analysis from an Observational and Retrospective Study. BMC Urology, 12, 19. http://dx.doi.org/10.1186/1471-2490-12-19

[37] Haab, F., Cardozo, L., Chapple, C. and Ridder, A.M. (2005) Long-Term Open-Label Solifenacin Treatment Associated with Persistence with Therapy in Patients with Overactive Bladder Syndrome. European Urology, 47, 376-384. http://dx.doi.org/10.1016/j.eururo.2004.11.004

[38] Cardozo, L., Amarenco, G., Pushkar, D., Mikulas, J., Drogendijk, T., Wright, M. and Compion, G. (2013) Severity of Overactive Bladder Symptoms and Response to Dose Escalation in a Randomized, Double-Blind Trial of Solifenacin (SUNRISE). BJU International, 111, 804-810. http://dx.doi.org/10.1111/j.1464-410X.2012.11654.x

[39] Chun, J.Y., Song, M., Han, J.Y., Na, S., Hong, B. and Choo, M.S. (2014) Clinical Factors Associated with Dose Escalation of Solifenacin for the Treatment of Overactive Bladder in Real Life Practice. International Neurourology Journal, 18, 23-30. http://dx.doi.org/10.5213/inj.2014.18.1.23

[40] Burger, M., Betz, D., Hampel, C. and Vogel, M. (2014) Efficacy and Tolerability of Solifenacin in Men with Overac- 
tive Bladder: Results of an Observational Study. World Journal of Urology, 32, 1041-1047. http://dx.doi.org/10.1007/s00345-013-1179-z

[41] Sanchez-Ballester, F., Miranda, P., Lizarraga, I., Rejas, J. and Arumi, D. (2014) Therapeutic Benefit in Patients Switching Tolterodine to Other Novel Antimuscarinic Agents. Actas Urológicas Españolas, 38, 156-163.

http://dx.doi.org/10.1016/j.acuroe.2013.12.001 